\title{
Aspects of the oceanography of shelf seas
}

\section{Henry Charnock}

The North-West European Shelf Seas: The Sea Bed and the Sea in Motion. Vol.II, Physical and Chemical Oceanography, and Physical Resources. Edited by F.T. Banner, M.B. Collins and K.S. Massie. Pp.337. (Elsevier Scientific: 1980.) Dfl.185, $\$ 90.25$.

IN THIS addition to the Elsevier Oceanography Series, five specialists deal with the tides, the wave climatology and with the physical oceanography of the Irish Sea, the North Sea, and the Celtic Sea and English Channel. One chapter deals with tidal power and a further seven are devoted to trace metals, to artificial radioisotopes, to sediment transport and to chemical and seabed resources (other than hydrocarbons). Volume I of this two-volume set dealt with the geology and sedimentology of the same area.

The physical oceanography contributions (Irish Sea by Bowden, Celtic Sea and English Channel by Pingree, and North Sea by Lee) are complementary, treating the same types of phenomena from different points of view. Coastal oceanography is clearly more complicated, if not more difficult, than that of the deep ocean: conditions are much less homogeneous so that it is difficult to study idealized processes. But the economic and aesthetic

\section{Can the U.S. stop advancing when Russia is advancing nuclear power?}

\section{FROM SCIENTIFIC SEARCH TO ATOMIC INDUSTRY}

\section{By A. M. Petrosyants}

388 pages $6 \times 9$ Hardbound $\$ 17.90$

This is a historical reference book to make the USSR'S nuclear science and nuclear power development understood. Some proRussia interpretation is evident, but it gives the objective reader on the USSR, understanding and a comparison to USA technology.

Flease send me copies of
FROM SCIENTIFIC SEARCH
TO ATOMIC INDUSTRY
@ 17.90 each. TOTAL COST $\$$
Payment in full enclosed
Make check Payable to
AMERICAN NUCLEAR SOCIETY
555 N. Kensington Ave. DEPT. 5
La Grange Park. Illinois 60525

Circle No.14 on Reader Enquiry Card. importance of some of the problems has led to an increase in the effort being put into trying to solve them: the numerical model succinctly described by Pingree should prove an increasingly valuable tool. Similar models are referred to by Huntley in his scholarly chapter on tides.

Of the other chapters, those on wave climatology (Draper), trace metals (Burton, Young) and artificial radioisotopes (Mauchline) are essentially factual. It is especially in these chapters that the delay between the preparation of the book and its publication is to be regretted; new measurements are being made, and old results updated, at a gratifyingly rapid rate.

Contributions on sediment transport and seabed resources (both by Banner) and the extraction of inorganic materials (Massie) illustrate the possibilities for exploitation of the ocean. They should be read in the context of the other chapters and in particular with that on socio- economic development and the management of coastal zones, by Harding, which gives a good account of how difficult it is to use the ocean wisely, even (especially?) in a confined region bounded by developed nations. The north-west European shelf seas (and perhaps especially the North Sea) represent a microcosm of what is increasingly recognized as a global problem of the future.

Since this region is one of the relatively few with large tidal range, it was perhaps sensible to include a chapter on tidal power (by Wilson). This gives a clear account of the Rance Scheme, of the USSR experience and of the UK prospects, but could be better appreciated if there was a related account of wave energy, and perhaps of wind power.

There is, one supposes, rather little in this book which could not be found elsewhere, but it is convenient to have the material gathered together into one volume.

Henry Charnock is Professor of Physical Oceanography at the University of Southampton.

\section{Mycotoxin biosynthesis reviewed}

\section{E. Arthur Bell}

The Biosynthesis of Mycotoxins: A Study in Secondary Metabolism. Edited by Pieter S. Steyn. Pp.432. (Academic: 1980.) \$44, $\$ 24.80$.

WIDESPREAD interest in the mycotoxins dates from the discovery of the aflatoxins in the early 1960s. Since then much has been published on these compounds and, as Sir Derek Barton states in his foreword to this volume, "the time is certainly ripe for an authoritative book". The present "authoritative book" is a collection of chapters written by leading workers in the field.

In the first chapter Bu'Lock discusses mycotoxins as secondary metabolites derived variously from polyketides, peptides, terpenes and other precursors. He emphasizes, moreover, that secondary metabolism, including mycotoxin biosynthesis, can be affected dramatically not only by the genetic modification of a fungus but also by the conditions under which the organism is grown or has been grown in the past. In succeeding contributions specific groups of mycotoxins are dealt with in detail. The biosynthesis of lysergic acid and the ergolines in Claviceps species is the subject of a contribution by Floss and Anderson. The formation of tricothecenes from mevalonate via farnesyl pyrophosphate in the Fungi Imperfecti is discussed by Tamm and Breitenstein, while Steyn, Vleggaar and Wessels describe the various techniques which have been used to elucidate the pathways of aflatoxin synthesis from polyketide precursors.

The ergochromes, also of polyketide origin, are dealt with by Franck, while Yamazaki provides us with information concerning a heterogeneous collection of neurotropic mycotoxins, including aspergillic acid, which is formed from leucine and isoleucine, and slaphramine, a lysine derivative.

The biosynthesis of patulin and penicillic acid is considered by Zamir and that of the cytochalasans, a group of mixed biosynthetic origin, by Tamm. Kirby and Robins write of gliotoxin and related compounds, Holzapfel of cyclopiazonic acid, and Sankawa of the anthraquinonoid mycotoxins. The final chapter by Vleggaar and Steyn on "miscellaneous mycotoxins" provides even more evidence of the diversity of the biochemical pathways which lead to these fungal products.

It is a pity that the reader is given so little information about the physiological effects produced by these compounds and the nature of the organisms to which they are toxic. Biosynthesis is, however, the proclaimed subject of the book and the editor and authors have provided us with a veritable mine of information on the subject. This book will prove invaluable to all chemists, biochemists and biologists interested either in secondary metabolism or in the toxins of the fungi.

E. Arthur Bell is Professor of Biology at King's College, University of London. 